\title{
"Portugal, Espanha, o volfrâmio e os beligerantes durante e após a Segunda Guerra Mundial" "
}

\author{
JOÃO PAULO AVELÃS NUNES \\ Universidade de Coimbra
}

\section{Introdução}

Visa o presente artigo analisar, de forma comparativa, o modo como, no Portugal do Estado Novo e na Espanha do Nuevo Estado, se estruturaram e foram enquadrados - pelos Governos e aparelhos de Estado respectivos, pelos grupos de países em conflito, com destaque para o Reino Unido/EUA versus Alemanha - os fenómenos sociais-globais habitualmente designados por booms do tungsténio ou "corridas ao volfrâmio".

${ }^{1}$ Versão resumida do texto da comunicação com o mesmo título apresentada no Encontro "Relações Portugal-Espanha: cooperação e identidade" (Zamora, 1 e 2 de Outubro de 1999), organização do CEPFAM/CEPESE da Universidade do Porto e da Fundação Rei Afonso Henriques. 
Tratou-se, no contexto da guerra económica progressivamente total que decorreu, a nível mundial, entre 1939 e 1945, de situações resultantes do crescimento da importância estratégica dos jazigos europeus de minérios de tungsténio; do correspondente aumento exponencial da procura, preços e oferta dos mesmos - extracção, separação e concentração, transporte, comercialização, armazenamento e exportação (através de métodos legais ou ilegais, envolvendo agentes individuais, empresas de dimensões diversas, entidades públicas).

Para além do peso relativo que assumiram nas economias de guerra de ambas as "neutrais" nações ibéricas - evolução das balanças comerciais e de pagamentos, intensificação de tendências inflacionistas, reforço da capacidade para negociar o fornecimento de bens essenciais, acesso a novos recursos financeiros por parte dos Governos e de empresas/particulares, emergência de fenómenos (sobretudo conjunturais) de mutação tecnológico-económica e sócio-mental, etc. -, os processos em causa tiveram, ainda, implicações significativas em áreas como o relacionamento diplomático-militar e político-ideológico com o Eixo e os Aliados, a receptação (directa ou indirecta) de ouro e outros bens pilhados pelo Terceiro Reich, a transição para o sistema bipolar do pós-guerra.

\section{1 - Produção científica e debates ideológicos}

No que diz respeito a Portugal, a investigação sobre os assuntos atrás referidos, tornada possível pela Revolução de 25 de Abril de 1974, acabou por 'arrancar' a partir de meados da década de 80 . Tem-se desenvolvido, seguindo os contributos pioneiros de Fernando Rosas, António José Telo e Douglas Wheeler, através da utilização de documentação - sobretudo de arquivo, impressa e oral, em menor grau, gráfica, audio-visual e material - nacional, britânica, norte-americana, francesa e espanhola. 
António Louçã constitui, no fundamental, uma excepção ao considerar, também, espólios alemães e suíços².

Em termos das limitações ainda hoje existentes, no nosso país, ao estudo destas e de outras questões de história recente, para além do estrutural sub-investimento e consequente sub-desenvolvimento das ciências sociais e da preservação do património documental, talvez sejam de salientar:

, a) o reduzido número de livros de memórias escritos por actores ou espectadores privilegiados dos acontecimentos; a censura à imprensa e outras modalidades repressivas impostas entre 1926 e 1974; o carácter lacunar de muitos dos espólios de natureza pública sobreviventes, resultado dos hábitos de secretismo, de escamoteamento dos obstáculos e divergências internos impostos durante a ditadura chefiada por António de Oliveira Salazar e Marcelo Caetano;

b) a dificuldade ou impossibilidade de consulta de grande parte dos núcleos arquivísticos, deliberadamente destruídos ou vítimas de incúria generalizada e sistemática; desaparecidos ou inacessíveis por falta de inventariação e tratamento, por ausência de autorização ${ }^{3}$.

Apesar dos trabalhos entretanto realizados (publicados ou apenas reproduzidos em quantidades limitadas) e do empenhamento de alguns

${ }^{2}$ Cfr., entre outros, J.L. Barros, 1993; O fim da Segunda Guerra Mundial [...], 1996; História [...], Maio de 1995; H.P. Janeiro, 1998; J.C. Jimenez Redondo, 1996; M. Liechti, 1997; M. Loff, 1997; A. Louçã, 1997b; A. Louçã, 1999a; I.F. Nunes, 1993; J.P.A. Nunes, s.d.; P.A. Oliveira, 1998; F. Peter, 1995; Portugal na Segunda Guerra Mundial [...], 1989; F. Rollo, 1994; F. Rosas, 1990; F. Rosas, 1994; G.A. Stone, 1994;A.J.Telo, 1987; A.J. Telo, 1991; A.J. Telo, 1996; N. Valério, 1994; Vértice [...], Novembro/Dezembro de 1995; A. Vilar, 1998; D.L. Wheeler, 1986.

Quanto a estudos mais antigos, elaborados sem possibilidade de acesso aos arquivos ibéricos, cfr., nomeadamente, D.L. Gordon, 1947; J.H. Kemler, 1949; W.N. Medicott, 1952-1959; J.K. Sweeney, 1974.

${ }^{3}$ Cfr., nomeadamente, História [...], Abril de 1995; M.F. Rodrigues, 1993; A.J. Telo, 1999. 
investigadores, de intervenções esporádicas por parte de diversos mass media, é quase inexistente entre nós - sociedade em geral e comunidade científica em particular - a reflexão teórica e, ao mesmo tempo, ético-cultural acerca de temáticas plenas de conexões com a actualidade.

Destacar-se-iam a natureza da Primeira República, Ditadura Militar e Estado Novo; as características da Igreja e da "acção católica" sob a liderança, no plano nacional, do Cardeal Manuel Gonçalves Cerejeira; as estratégias das associações patronais e dos empresários entre 1910 e 1974; a(s) postura(s) adoptada(s) pelo regime e pelo país durante e imediatamente após a Segunda Guerra Mundial; o "ouro nazi", os cidadãos e os "bens alemães" nos Estados "neutrais" versus os crimes do Terceiro Reich; o anti-semitismo e a atitude assumida perante a forma como a "Grande Alemanha" lidou com o então designado "problema judaico".

Ilustrativo deste mesmo quase-silêncio, de um "revisionismo historiográfico" com fortes apoios em múltiplos centros de poder, é a forma como sucessivos Governos têm procurado afirmar a inexistência e impedir a análise objectivante das questões formuláveis a propósito da política económico-financeira e das relações externas do Estado Novo entre 1939 e 1945; do "ouro nazi", dos cidadãos e "bens alemães" nos Estados "neutrais" durante e após a Segunda Guerra Mundial.

A peculiaridade da realidade portuguesa - apenas superada pela Turquia -, torna-se, ainda, mais clara se a confrontarmos com o ocorrido, a este mesmo propósito, na Suíça, Suécia, Espanha e Argentina (países "neutrais"); Alemanha/Áustria e Itália (potências invasoras), Dinamarca, Noruega, Holanda, Bélgica e França (países derrotados pelo Eixo mas sujeitos a uma ocupação significativamente menos violenta do que aquela de que foram vítimas as nações da Europa de Leste e Balcânica); Reino Unido e Estados Unidos da América ${ }^{4}$.

${ }^{4}$ Cfr., entre outros, R.Afonso, 1990; A. Beker, 1997; T. Bower, 1997; Dagens Nyhether [...], 21 de Outubro de 1997; The Deutsche Bank [...], 1998; Y. Durand, 1990; Enter- 
Em Espanha, dada a longevidade do regime franquista, a evolução da historiografia acerca do século XX em geral e, em particular, sobre a participação daquele país na Segunda Guerra Mundial poderia ter sido paralela à ocorrida em Portugal. Para além de uma intervenção mais alargada de estudiosos de outros países, parece, no entanto, ser possível detectar outras diferenças: maior desenvolvimento das ciências sociais, menores dificuldades de acesso a documentação (impressa ou nãoimpressa, escrita ou outra), recurso frequente aos arquivos alemães; inferior peso relativo das concepções "revisionistas", aceitação da necessidade de participação no esforço internacional de estudo e debate cívico das temáticas da neutralidade/não-beligerância, do "ouro nazi", dos cidadãos e "bens alemães" nos Estados "neutrais" a partir de $1939^{5}$.

\section{2 - Gestão dos "dossiers volfrâmio" durante a Segunda Guerra Mundial}

Simplificando, embora, o grande número de intervenientes, a diversidade de propósitos e a complexidade de relações estabelecidas, é

prises in the period of fascism in Europe [...], 1998; M. Fior, 1996; M. Gilbert, 1989; D.J. Goldhagen, 1997; W. Grant, 1991; M. Harrison, 1998; S.F. Hedin, 1997; Informe para la Comisión [...], 1998; J.C. Leite, 1997; A. Louçã, 1995; A. Louçã, 1996; A. Louçã, 1997a; A. Louçãa, 1997b; A. Louçã, 1999a; A. Louçãa, 1999b; A. Louçã, 1999c; A. Louçã, 1999d; M.H. Mello, 1982; G. Miedzianagora, 1995; R.L. Miller, 1997; The nazi gold and the Swedish Riksbank [...], 1998; R.O. Paxton, 1992; I. Pimentel, 1998; I. Pimentel, 1999; Relatório da Comissão [...], 1999; F. Rosas, 1999; M. Ruby, 1998; Sweden and jewish assets [...], 1999; Switzerland and gold transactions in the Second World War [...], 1998; A.J. Telo, 1999; U.S. and Allied efforts to recover and restore gold [...], 1997/1998; J. Ziegler, 1997.

Na Argentina, através do Decreto $\mathrm{n}^{\circ}$ 390/97 (Maio de 1997), foi criada a Comision Para el Esclarecimiento de las Actividades del Nazismo en la Republica Argentina. Em 1998, tinham sido estruturadas no âmbito da mesma e prosseguiam a sua actividade 16 unidades de investigação, coordenadas por especialistas argentinos e estrangeiros.

Cfr., nomeadamente, J. Catalan, 1995; M. Espadas Burgos, 1988; R. García Pérez, 1994; Informe para la Comisión [...], 1998; J.C. Jiménez Redondo, 1996; Ch. Leitz, 1996; M. Loff, 1997; P. Preston, 1995; K.-J. Ruhl, 1986. 
possível ensaiar um esboço de caracterização do modo como ambas as ditaduras peninsulares geriram, durante a Segunda Guerra Mundial, as respectivas "corridas ao volfrâmio". Uma vez mais, tratou-se de fenómenos simultaneamente paralelos e com algumas diferenças significativas ${ }^{6}$.

Desde Setembro de 1939 até à rendição da França, em Junho de 1940, o mercado português do tungsténio foi hegemonizado pelo Aliados, consequência da capacidade de bloqueio das vias terrestres e marítimas de ligação entre Portugal e a Alemanha, do controlo accionário ou posse das principais sociedades mineiras, do facto de o Terceiro Reich manter o acesso aos fornecedores latino-americanos e aos grandes produtores asiáticos - através da União Soviética.

O Eixo passou, então (Julho de 1940), a poder transportar os bens adquiridos e fornecidos a Portugal através da Espanha e de França, voltando, com maior intensidade, a investir em empresas concessionárias e outras. Apesar da "legislação de excepção" entretanto publicada, até ao primeiro trimestre de 1942 as actividades económicas ligadas à mineração do volfrâmio continuaram a desenvolver-se quase sem intervenção acrescida por parte do Estado ou de organismos corporativos. Se, por um lado, o regime respeitou as posições alcançadas e os equilíbrios estabelecidos nas décadas anteriores - favoráveis ao Reino Unido -, por outro assegurou aos (ou tolerou por parte dos) beligerantes quase total liberdade de acção no terreno.

'Cfr., entre outros, J. Catalan, 1995; Dez anos de política externa [...], 1961-1993; R. García Pérez, 1994; D.L. Gordon, 1947; Informe para la Comisión [...], 1998; J.H. Kemler, 1949; Ch. Leitz, 1996; K.C. Li, 1955; W.N. Medlicott, 1952-1959; J.P.A. Nunes, s.d.; F. Peter, 1995; J.A. Rodrigues Pérez, 1985; F. Rosas, 1990; K.-J. Ruhl, 1986; J.M. Ruiz Morales, 1946; J.K. Sweeney, 1974; A.J. Telo, 1991; A.J. Telo, 1999; U.S. and Allied efforts to recover and restore gold [...], 1997/1998; A. Vicente, 1992; A. Vilar, 1998; D.L. Wheeler, 1986. 
A 20 de Novembro de 1940, o Banco de Portugal e o Bank of England assinaram um Acordo de Pagamentos, válido enquanto durasse a confrontação militar, que garantiu ao Estado e às empresas britânicos crédito ilimitado em escudos para compras a realizar em Portugal. Tendo-se recusado a negociar um Acordo Comercial de Guerra com Londres, o Governo chefiado por António de Oliveira Salazar acabou, no entanto, por aceitar, desde 28 de Janeiro de 1941, que as relações entre ambos os países seriam, em princípio, geridas de acordo com as regras do bloqueio económico, definidas pelo Ministry of Economic Warfare.

No que diz respeito ao Estado nacional-socialista, para além das alterações resultantes do seu alargamento aos "territórios" que, uma vez anexados, foram passando a integrar o Terceiro Reich, manteve-se sempre em vigor o Acordo para Liquidação de Créditos Comerciais assinado a 13 de Abril de 1935. De certa forma imposto por Berlim, configurou um sistema de clearing bilateral gerido por cada um dos bancos centrais e Governos.

Mesmo tendo em conta o aumento das importações de bens portugueses de interesse estratégico - entre os quais começavam a destacar-se o estanho e o tungsténio -, nos anos de 1939/1940 e primeiro semestre de 1941 o saldo da balança comercial entre os dois países continuou favorável à Alemanha. Este fenómeno, contraditório com a lógica de endividamento externo tendencialmente adoptada por todos os Estados beligerantes, ocorreu, apenas, nas duas fases iniciais do conflito, devido à renovação dos contratos de fornecimento de armas e de tecnologia para a indústria militar negociados com Lisboa a partir de 1937.

A invasão da URSS (iniciada a 22 de Junho de 1941) e a entrada dos EUA na guerra (7 a 11 de Novembro de 1941) implicaram uma alteração decisiva da situação internacional e da posição de Portugal no seio da mesma. Tratou-se, para além do mais, de uma redução drástica dos contactos comerciais da Alemanha, quer com a América Central e do 
Sul, quer com a Ásia. Os jazigos de volfrâmio localizados na Europa predominantemente em Portugal e na Espanha - adquiriram, então, para o Terceiro Reich, uma importância decisiva.

Apesar do 'sobreaquecimento' já antes atingido, voltaram a 'disparar', tanto os valores da procura, dos preços e da oferta de minérios de tungsténio, como os níveis de intervenção - directa e notória - dos dois grupos beligerantes. Toda esta actividade implicava o envolvimento de cidadãos estrangeiros e nacionais, das representações diplomáticas, serviços secretos e de propaganda; redes de empresas (com destaque para a Beralt Tin \& Wolfram), colaboradores individuais e parceiros comerciais - coordenados, respectivamente, pela United Kingdom Commercial Corporation e pela Minero-Silvícola (propriedade do Estado nacional-socialista através da holding Rowak/Sofindus).

De Outubro de 1941 a Junho de 1942, o Governo português legislou e adoptou medidas político-administrativas visando recuperar a capacidade de controlar o universo do volfrâmio. Por motivações próprias e em resposta a pressões oriundas, sobretudo, da Alemanha, procurou com empenho direccionado, meios limitados e, consequentemente, sucesso parcial - proibir a exploração mineira 'informal' durante as fases mais intensas dos ciclos agrícolas, reduzir o número de trabalhadores rurais envolvidos, concentrar num círculo restrito de organismos oficiais a efectiva capacidade de manipular variáveis como a propriedade de empresas e concessões, o direito de exploração, o financiamento, a produção, os preços, a comercialização, a circulação, a semi-transformação, a exportação e a tributação/taxação.

Sob a orientação do próprio António de Oliveira Salazar - Presidente do Conselho, Ministro dos Negócios Estrangeiros e Ministro da Guerra, despachando directamente com o Subsecretário de Estado das Corporações e Previdência Social, com os Directores da Polícia de Vigilância e Defesa do Estado e do Secretariado de Propaganda Nacional -, dos 
Ministros das Finanças, Economia, Interior e Obras Públicas, Transportes e Comunicações, foram, neste âmbito, reforçados os poderes da Direcção Geral de Minas e Serviços Geológicos e Circunscrições Mineiras; Comissão Reguladora do Comércio dos Metais; Direcção Geral da Indústria e Circunscrições Industriais; Instituto Nacional do Trabalho e Previdência; Direcções Gerais dos Caminhos de Ferro e dos Transportes Terrestres; Inspecção do Comércio Bancário do Ministério das Finanças e Banco de Portugal; governos civis e câmaras municipais/juntas de freguesia, repartições de finanças, forças policiais e tribunais.

A 24 de Janeiro de 1942, o Estado Novo assinou com o Terceiro Reich um acordo sobre tungsténio. Válido entre 1 de Março de 1942 e 28 de Fevereiro de 1943, fixava as quantidades a exportar, definia as "explorações livres" e as minas controladas pelos beligerantes, delimitava a percentagem de "minérios livres" a entregar a cada contendor. Resultou na troca de concentrados portugueses por outros produtos alemães e, apenas em último caso, por divisas convertíveis ou ouro. Só em 24 de Agosto de 1942 foi concretizada uma iniciativa do mesmo tipo com o Reino Unido, seguindo-se um Acordo de Fornecimentos-Compras e um Acordo Comercial de Guerra com os Aliados (23 e 27 de Novembro de 1942).

Algo de semelhante voltou a acontecer em 1943, apesar da crescente inferioridade militar do Eixo, das reforçadas exigências anglo-americanas e da diferente configuração assumida pelo "dossier volfrâmio" na vizinha Espanha: acordo com Berlim a 21 de Abril de 1943 - tendo vigorado de 1 de Março de 1943 ao fim de Fevereiro de 1944 -; duas prorrogações do acordo luso-britânico sobre tungsténio, dos Acordos de Fornecimentos-Compras e Comercial de Guerra com os Aliados (até Dezembro de 1943); concessão de facilidades militares ao Reino Unido nos Açores (18 de Agosto de 1943).

Remetendo para dados oficiais - continua a não ser possível estimar 
o volume alcançado pelas "actividades ilegais e clandestinas" (muitas vezes toleradas, ou, mesmo, patrocinadas pelas autoridades) -, lembram-se alguns dos resultados materiais de todo este conjunto de decisões, iniciativas e actividades. Portugal teria produzido $4500 \mathrm{t}$ de concentrados no ano de 1940, 4607t em 1941, 4120t em 1942 (quebra decorrente dos controlos e do tabelamento de preços introduzidos pelo Governo), 5563t em 1943 e 3214t até Junho de 1944?

Seriam os seguintes os números das exportações de volfrâmio: $3443 \mathrm{t}$ no total em 1940, 1783t para o Reino Unido, 768t para os EUA, 540t para França e 185t para a Alemanha, entre outros; 5235t no total em 1941, dos quais 2363t para o Reino Unido, 1814t para a Alemanha, 848t para os EUA, entre outros; 4801t no total em 1942, dos quais 2589t para o Reino Unido, 2169t para a Alemanha e 43t para a Itália; 6669t no total em 1943, dos quais 5321t para o Reino Unido e 1342t para a Alemanha, entre outros; 2688t no total em 1944, dos quais 1987t para o Reino Unido e 701t para a Alemanha. Nos anos de 1943 e 1944, o Terceiro Reich importou, ainda, 34t e 77t de resíduos de tungsténio ${ }^{8}$.

Tendo em conta, a dimensão dos interesses envolvidos, as características sócio-económicas e culturais das "regiões do volfrâmio", os preços atingidos e as modalidades de actuação dos dois regimes - com evoluções desfazadas em ambos os lados da fronteira luso-espanhola -, não é difícil admitir que, em termos da produção, comercialização ("contrabando interno"), semi-transformação, transporte e exportação (contrabando local, organizado pelos beligerantes ou "oficioso"), do financia-

De acordo com K.C. Li e Chung Yu Wang, o nosso país teria sido responsável, entre 1940 e 1945, pela extracção, transformação e exportação das seguintes quantidades de concentrados contendo $60 \% \mathrm{WO}_{3}: 4858 t, 5834 t, 5220 t$, 7477t, 4088t, 0t (Cfr. K.C. Li, 1955, p. 420)

${ }^{8}$ Cfr. Comércio Externo e relatório não impresso existente no Arquivo do Instituto Geológico e Mineiro. 
mento e dos pagamentos internacionais (envolvendo ouro), essas "actividades ilegais e clandestinas" deverão ter alcançado montantes muito significativos. A Alemanha desde 1940, os Aliados a partir de 1943, estruturaram mecanismos de intervenção que cobriam a Península Ibérica no seu conjunto.

No dia 5 de Junho de 1944, encerrou-se um longo e difícil processo negocial de mais de seis meses durante o qual Reino Unido e os EUA, perante a ineficácia das pressões económicas e diplomáticas, chegaram a aceitar a necessidade de apoiar o derrube do Estado Novo, ou, pelo menos, de António de Oliveira Salazar. Abandonando diversos objectivos que considerava serem essenciais, o Governo português informou o embaixador britânico em Lisboa de que cedia perante as exigências dos Aliados e determinaria a suspensão da produção e exportação de concentrados de tungsténio. Em 26 de Janeiro de 1945, Portugal e os Aliados assinaram um novo Acordo de Fornecimentos-Compras, a 8 de Agosto de 1945, o Banco de Portugal e o Bank of England renegociaram o Acordo de Pagamentos de 1940.

Através do Decreto-Lei n. ${ }^{\circ}$ 33: 707, de 12 de Junho de 1944, foi imposta a suspensão de todo o tipo de actividades - produção, comercialização, transporte, semi-transformação, exportação - em torno dos minérios de volfrâmio. As quantidades já extraídas seriam obrigatoriamente entregues à Comissão Reguladora do Comércio dos Metais nos prazos e pelos preços definidos por legislação anterior.

Esta forçada inactividade só terminou em Dezembro de 1945/Janeiro de 1946, depois de ter sido assegurada a venda das reservas acumuladas pela Comissão Reguladora do Comércio dos Metais. Apesar do agravamento das penas aplicáveis, o contrabando de concentrados para a Alemanha continuou, pelo menos, até Agosto de 1944, aquando da libertação do Sul de França pelos Aliados e do encerramento da fronteira dos Pirinéus. 


\section{João Paulo Avelãs Nunes}

Nos anos de 1939 a 1941, o subsector espanhol do volfrâmio teria sido marcado pelos seguintes vectores de evolução conjuntural: aumento da procura e correspondente tendência para a subida dos preços/ crescimento da oferta; legislação limitadora da penetração de capitais estrangeiros mas aceitação de facto da aquisição de empresas e concessões mineiras pelo Grupo Rowak/Sofindus - herdeiro do sistema HismaRowak, criado durante a Guerra Civil'; quase-monopólio na importação por parte do Terceiro Reich e desinteresse do Reino Unido/EUA; tabelamento do preço dos concentrados pelo Governo (no âmbito de acordos hispano-germânicos?) e grande importância das actividades clandestinas - extracção, comércio interno, contrabando para Portugal e para a Alemanha ${ }^{10}$.

Em 1942 e 1943, perante a alteração da situação militar e as pressões dos Aliados, alguma desilusão com a postura neo-colonial adoptada pelo Terceiro Reich, a necessidade de garantir o fornecimento de bens essenciais, o empenhamento em assegurar a sobrevivência do regime qualquer que fosse o resultado final do conflito, o Governo de Madrid modificou, em parte, as regras antes definidas para ó mercado nacional do tungsténio. Tratou-se, ainda, de uma estratégia de potenciação das vantagens económico-financeiras inerentes ao estatuto de neutralidade

' Compañia Hispano Marroqui de Transportes (Hisma), fundada em Tetuão a 31 de Julho de 1936, dirigida por Fernando Carranza e Joannes Bernhardt em representação das forças "nacionalistas" sublevadas e do Terceiro Reich (Gabinete do Plano Quadrienal), extinta a 31 de Dezembro de 1940. Rohstoffe und Ware Einkaufsgelleschaft (Rowak). constituída em Berlim a 7 de Outubro de 1937, tutelada pelos Gabinete do Plano Quadrienal e Ministério da Economia. Sociedad Financiera Industrial (Sofindus), fundada cm Lisboa c registada em Salamanca em Novembro de 1938, propriedade da Rowak e dirigida por Joannes Bernhardt, integrando empresas dos sectores comercial, de transportes e mineiro (maioritário).

${ }^{10}$ Cfr. J. Catalan, 1995, p. 185/186; Informe para la Comisión [...], 1998, p. 161/ 162; J.M. Ruiz Morales, 1946, p. 49/50. 
- readoptado no seguimento da substituição de Ramón Serrano Suñer pelo General Francisco Gómez-Jordana no cargo de Ministro de Asuntos Exteriores (3 de Setembro de 1942).

Apesar da publicação de mais legislação "nacionalizadora" da actividade mineira (1942), a tolerância para com os encapotados investimentos estrangeiros foi alargada ao Reino Unido e aos EUA, os quais, para além da actividade indirecta da United Kingdom Commercial Corporation e da United States Commercial Corporation, formaram, em Outubro desse mesmo ano, a empresa holding Sociedad Anónima Financiem e Industrial. As aquisições preemptivas concretizadas pelos Aliados fizeram disparar a produção e o valor dos minérios transaccionados.

Conjugando a liberalização dos preços com a elevação da taxa sobre a exportação de concentrados de volfrâmio (100 pesetas por quilograma a partir de 7 de Janeiro de 1943); reforçando os mecanismos de fiscalização através da criação, em Julho de 1941, do Consejo Ordenador de Minerales Especiales de Interés Militar - que duplicou as estruturas já existentes, dependentes, tanto da pasta da Industria y Comercio, como dos ministérios que tutelavam as forças policiais, os tribunais, as autoridades locais e regionais -, foi possível limitar o peso relativo dos "circuitos paralelos", ajudar a inverter os fluxos predominantes do contrabando para o sentido Portugal-Espanha", aumentar de forma significativa as receitas do Estado.

Durante os segundo e terceiro trimestres de 1943, perante o incumprimento de aspectos considerados essenciais dos dois acordos comerciais

" Uma tal alteração resultou, igualmente, as medidas tomadas pelo Governo de Lisboa no final de 1941/início de 1942: tabelamento do preço dos concentrados, monopólio legal da sua comercialização por parte da Comissão Reguladora do Comércio dos Metais, negociação de acordos sectoriais com a Alemanha e com o Reino Unido/EUA. 
e de pagamentos negociados desde o fim da Guerra Civil, o Governo de Madrid deixou de conceder créditos em pesetas às entidades alemãs responsáveis pela aquisição de "tungsténio livre" espanhol. O Terceiro Reich viu-se, pois, limitado aos concentrados produzidos nas minas próprias e a pequenas quantidades adquiridas de forma ilegal (com ouro ou a partir de Portugal, em escudos).

Inversamente, os Aliados optaram por garantir ao regime chefiado pelo General Francisco Franco níveis de fornecimento de bens essenciais suficientes para tentar desincentivar, quer a entrada da Espanha no conflito (ao lado do Eixo), quer retaliações contra os avultados investimentos britânicos; para assegurar a capacidade de concretização de compras massivas de produtos estratégicos - obtidos através de meios legais ou ilegais, por necessidade própria ou dentro de uma lógica preemptiva ${ }^{12}$. Puderam, assim, obter mais volfrâmio (grande parte do qual não foi exportado) e negociar contratos em que os concessionários se comprometiam a limitar a actividade extractiva.

A partir do Outono de 1943, no entanto, Reino Unido e EUA - os segundos com maior veemência do que os primeiros - passaram a exigir o embargo das vendas de tungsténio espanhol à Alemanha. Mostraram-se, também, dispostos a assegurar, simultaneamente, um aumento dos fornecimentos e modalidades de compensação dos prejuízos causados pela diminuição das exportações. Em caso de resposta negativa, ameaçavam com o corte das vendas de trigo, petróleo e algodão, o que veio a acontecer em Janeiro de 1944, dada a recusa inicial de Madrid em negociar.

${ }^{n}$ A título de exemplo de um conjunto de compromissos, de natureza global ou parcelar, alcançados por Londres/Washington e Madrid entre 1940 e 1944 - por vezes com a participação de Lisboa -, citam-se o Acordo Comercial de Guerra e o Acordo de Pagamentos de 18 de Março de 1940. 
Para esta modificação da estratégia de guerra económica seguida na Península Ibérica, terão contribuído, entre outros, os seguintes factores: crescente supremacia militar e eminência da abertura de uma "segunda frente" na Europa Ocidental, níveis de endividamento resultantes das aquisições preemptivas a preços inflacionados e incapacidade para anular as importações alemãs de volfrâmio e de outros bens estratégicos, iniciativas do Executivo franquista visando o relançamento do intercâmbio hispano-germânico.

Refira-se, sobretudo, o protocolo de 18 de Agosto de 1943 - parcialmente prorrogado a 30 de Novembro de 1944 -, nos termos do qual o Terceiro Reich se comprometeu a cumprir, de forma mais cabal, o previsto nos Acordos Comerciais e de Pagamentos de 22 de Dezembro de 1939 e de 16 de Dezembro de 1942: fornecimento de máquinas-ferramentas, armamento, apoio ao desenvolvimento das indústrias química e militar, etc, em troca da venda de matérias-primas estratégicas e da concessão de créditos de curto prazo.

Nessa mesma altura, aceitando proceder a uma nova amortização parcial da dívida acumulada durante a Guerra Civil, o Ministro de Industria y Comercio, Demetrio Carceller, viabilizou a entrega de 434 milhões de pesetas às agências alemãs em Espanha. Grande parte da verba em causa foi utilizada pela Sofindus na compra (legal ou clandestina) de "volfrâmio livre" entre o último trimestre de 1943 e meados de 1944.

Colocado perante as ameaças de colapso económico, de renascimento da conflitualidade social e política, do empenhamento externo no derrube da ditadura, o Governo do General Francisco Franco começou por decretar a suspensão das exportações de concentrados para o Terceiro Reich enquanto não fosse alcançado um acordo (Fevereiro a Abril de 1944). No dia 1 de Maio de 1944 o impasse foi superado. A Espanha aceitou, no essencial, as condições impostas pelos Aliados em termos de tungsténio, económicos em geral, militares e de serviços secretos. 


\section{$\underline{\text { João Paulo Avelãs Nunes }}$}

De forma a evitar uma situação de cedência total e a assegurar o empenhamento do aparelho de Estado no combate às actividades clandestinas, Madrid foi autorizada a manter a venda de poucas dezenas de toneladas mensais de volfrâmio a Berlim. No entanto, com maior ou menor colaboração das autoridades, a Sofindus e as estruturas diplomáticas alemãs reforçaram a sua capacidade de utilização de mecanismos ilegais de financiamento, aquisição, transporte e exportação. Numa escala significativa até ao fim de Junho de 1944, em termos residuais nos meses seguintes, todo esse conjunto de transacções terá sido pago em pesetas e ouro, através de circuitos que interligavam a Alemanha, Espanha, Portugal e, eventualmente, a Suíça.

Mau grado o carácter parcelar das estatísticas sobre o tungsténio espanhol durante a Segunda Guerra Mundial, referem-se algumas séries propostas por diversos autores. K.C. Li e Chung Yu Wang afirmam terem sido produzidas e comercializadas as seguintes quantidades de concentrados de volfrâmio contendo 60\% W $\mathrm{W}_{3}$ : 1940, 393t; 1941, 415t; 1942, 1462t; 1943,3902t; 1944,2393t; 1945,283t. J.A. Rodriguez Pérez aventa, para os mesmos anos, os dados que se seguem: 391t, 414t, 1511t, 4038t, $2474 t, 293 t$.

Remetendo para as Estadísticas de Comercio Exterior, Jordi Catalan divulga os números oficiais sobre exportação de concentrados: 563t, 156t, 159t, 1396t, 2502t, 1662t. Outros estudiosos apresentam alguns dados avulso ou de natureza hipotética: em 1942, Berlim comprou 1000t e os Aliados 760t; em 1943, os Aliados teriam adquirido 3050t (ou 3350t) e a Alemanha 1200t (ou 900t) - 3550t de Espanha e 700t contrabandeadas a partir de Portugal; em 1944, o Terceiro Reich importou 325t legalmente e 638t por vias ilegais, tendo as autoridades franquistas apreendido 103lt em armazéns propriedade de empresas do grupo Sofindus (Agosto de 1944) ${ }^{13}$.

"Cfr. K.C. Li, 1955, p. 420; J.A. Rodriguez Pérez, 1985, p. 70; J. Catalan, 1995, 


\section{3 - Condicionalismos e resultantes da "guerra do tungsténio"}

À semelhança do que acontecera de 1910 a 1918 - imediatamente antes e durante a Primeira Grande Guerra -, do que se verificaria entre o início da 'guerra fria' (1947) e o fim da Guerra da Coreia (1950-1953), também na Segunda Guerra Mundial e na fase de corrida aos armamentos/ "conflitos regionais" que a antecedeu (1934-1938 e 1939-1945) a "febre do volfrâmio" acarretou, para os dois países ibéricos, em maior escala, um conjunto de implicações (directas e indirectas) que interessaria explicitar melhor ${ }^{14}$.

Tratou-se, em primeiro lugar, da multiplicação do número de locais de extracção com os mais diversos tipos de relacionamento contratual com os trabalhadores, situação legal perante as autoridades, dimensões e níveis de complexidade; do crescimento das actividades económicas complementares. No caso das empresas de média e grande dimensão, ligadas a um dos grupos beligerantes, assistiu-se a processos de renovação organizacional e tecnológica, melhoria dos salários e das estruturas de apoio social, das infraestruturas de transportes e distribuição de energia.

Proliferaram as micro-explorações 'informais' (o "pilha"); modalidades complementares de extracção à superfície e separação manual

184; Informe para la Comisión [...], 1998; Ch. Leitz, 1996; W.N. Medlicott, 1952-1959; K.-J. Ruhl, 1986; U.S. and Allied efforts to recover and restore gold [...], 1997/ 1998; D.L. Wheeler, 1986.

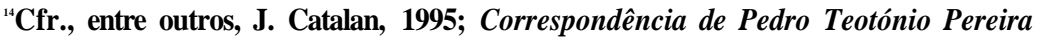
[...], 1987-1991; Dez anos de política externa [...], 1961-1993; O fim da Segunda Guerra Mundial [...], 1996; R. Garcia Pérez, 1994; Informe para la Comisión [...], 1998; H.P. Janeiro, 1998; J.P.C. Leite, 1943; Ch. Leitz, 1996; M. Loff, 1997; A. Louçã, 1999a; A. Louçã, 1999c; A. Louçã, 1999d; J.P.A. Nunes, s.d.; P.A. Oliveira, 1998; F. Peter, 1995; Relatório da Comissão [...], 1999; F. Rollo, 1994; F. Rosas, 1990; F. Rosas, 1996; K.-J. Ruhl, 1986; A.O. Salazar, 1945-1967; A.J. Telo, 1991; A.J. Telo, 1996; A.J. Telo, 1999; N. Valério, 1994. 
(o "quilo"), organizadas pelos próprios concessionários; sob a capa das licenças para pesquisas e, portanto, antes da publicação dos alvarás de concessão (da aceitação de um director técnico, da aprovação de um "plano de lavra"), a efectica exploração dos jazigos, em regime de "lavra ambiciosa" ou "lavra de rapina"; a falsificação, tanto de indicadores relativos às potencialidades das concessões, como de lotes de minério e de guias de trânsito; a semi-transformação e o comércio/transporte ilegais; os assaltos aos grandes coutos mineiros, os pequenos furtos por parte dos operários, as revoltas contra as proibições impostas pelas autoridades; a corrupção e o contrabando (interno ou externo).

Gerou o aumento do número de feridos, incapacitados e mortos por acidentes de trabalho, epidemias (febre tifóide, por exemplo) e, a médio prazo, doenças profissionais (sobretudo a silicose); a intensificação dos conflitos entre "interesses mineiros" e proprietários de terrenos em torno dos direitos de exploração dos jazigos, da destruição de culturas e árvores, da inviabilização das actividades agro-pecuárias, do desvio e poluição das águas; a ampliação de fenómenos de "criminalidade" e violência (roubos, rixas, utilização de armas de fogo, prostituição, "mercado negro" de produtos tabelados).

Com essas dezenas de empresas e centenas de milhar de pessoas que confluíram nas actividades e/ou áreas do tungsténio - a maioria das quais na qualidade defuncionários, capatazes, guardas, e operários, "apanhistas", comerciantes, contrabandistas, prostitutas; algumas idas dos centros urbanos ou de outros países, estas últimas com hábitos sociais e profissões raros ou desconhecidos no mundo rural (administradores, engenheiros, geólogos, contabilistas, tradutores, técnicos de máquinas e de análises a minérios, advogados, etc.) -, ocorreram situações muito diversas em termos de acesso aos e capacidade de fixação/aplicação dos capitais entretanto gerados. O esbanjamento total de "dinheiro fácil" e o enriquecimento fulgurante/a ascensão social, são, no entanto, as variantes 
mais glozadas da mitologia que se foi construindo em torno da figura do "volframista"-

A Alemanha e o Reino Unido/EUA disputaram, quer a compra de minérios e de concentrados no "mercado livre", quer a aquisição de empresas concessionárias/de novas concessões; montaram redes de contrabando, espionagem e propaganda; negociaram e/ou impuseram ameaçando com invasão, bombardeamento, afundamento ou apresamento de navios, bloqueio económico, suspensão de fornecimentos - acordos comerciais e de pagamentos internacionais, quotas de aquisição, modalidades de financiamento e transporte; denunciaram as actividades do bloco adversário e as facilidades concedidas pelas autoridades (eventualmente violadoras de compromissos assumidos e do estatuto de neutralidade).

Acarretou saldos positivos das balanças comerciais e de pagamentos, o aumento das quantidades de moeda em circulação e o crescimento da inflação, a ampliação das receitas dos Estados (impostos, taxas, emolumentos, empréstimos), a acumulação de recursos financeiros por parte de empresas e particulares; nas "zonas do tungsténio" e em regiões vizinhas, o fim do desemprego e do subemprego sazonal, o abandono (mais ou menos temporário) do trabalho na agricultura (em alguns casos, nas próprias fábricas e serviços), a modificação (mesmo que apenas episódica) dos equilíbrios sócio-mentais tradicionais, das formas de relacionamento com a actividade económica e dos hábitos de consumo de segmentos significativos das populações.

Durante a Segunda Guerra Mundial, o Governo de Lisboa e o Banco de Portugal decidiram, pois, conceder crédito ilimitado em escudos ao Reino Unido, pagável e correspondendo, em 1945, a cerca de 80 milhões de libras, com garantia e equivalendo a cerca de $280 \mathrm{t}$ de ouro; tiveram, ainda, possibilidade e optaram por adquirir ou aceitar como forma de pagamento quantidades significativas daquele metal precioso: $347,7 \mathrm{t}$ no 
total, das quais 167,5t (48,2\%) ao Federal Reserve Bank (Nova Iorque), $105,8 \mathrm{t}(30,4 \%)$ ao Banque Nationale Suisse (Berna), 48,9t (14,1\%) ao Deutsche Reichsbank (Berlim), entre outros.

O ouro e as divisas convertíveis provenientes, tanto do Deutsche Reichsbank, como do Banque Nationale Suisse, resultariam, no essencial, directa ou indirectamente, dos confiscos e pilhagens concretizados, de forma sistemática, pelo Terceiro Reich, nos países ocupados e/ou anexados antes e depois de 1 de Setembro de 1939, a bancos centrais, outras empresas e particulares, aos prisioneiros enviados para campos de trabalho e extermínio. Estados beligerantes e neutros estariam a par dessa situação. Por decisão de António de Oliveira Salazar e João da Costa Leite (Ministro das Finanças), a Alemanha apenas teria obtido no nosso país adiantamentos restritos, enquadráveis no mecanismo de clearing bilateral e equivalentes a empréstimos de curto prazo.

Dada a situação de muitos dos espólios nacionais relevantes Presidência do Conselho, Inspecção do Comércio Bancário, Polícia de Vigilância e Defesa do Estado, Banco Espírito Santo \& Comercial de Lisboa, Banco Lisboa \& Açores (Banco Totta \& Açores), etc. -, não tem sido possível estudar a actividade, legal ou clandestina ${ }^{15}$, tanto dos bancos comerciais portugueses e de outras empresas/particulares, como da representação diplomática e de sociedades de capitais alemães nos circuitos do "ouro nazi". Resta esperar por outros projectos de investigação que utilizem documentação germânica, suíça, britânica ou norteamericana.

Em Espanha, devido à pressão do Terceiro Reich no sentido da amortização da dívida acumulada durante a Guerra Civil, foram muito inferiores os quantitativos de ouro adquiridos no exterior, entre 1941 e

${ }^{15} \mathrm{O}$ Banco de Portugal passou a deter o monopólio legal da importação, exportação e reexportação de ouro em barra ou amoedado a partir de Junho de 1942. 
1946, por entidades oficiais. O Banco de España e o Tesoro (Ministerio de Hacienda), que detinham a responsabilidade da política monetária interna; o Instituto Español de Moneda Extranjera (Ministerio de Industria y Comercio), com o exclusivo do movimento de divisas e das importações/exportações daquele metal precioso: 67,4t no total, das quais 38,6t (57,3\%) ao Banque Nationale Suisse, 14,9t (22,1\%) ao Bank of England, 9,1t ao Banco de Portugal (13,5\%), 2,5t (3,7\%) ao Banco Alemán Transatlántico, entre outros.

Sem pretensões de exaustividade, foram já referenciadas situações concretas em que a Embaixada da Alemanha em Madrid, serviços de informações e o grupo Rowak/Sofindus estiveram envolvidos, nos anos de 1944 e 1945, em operações, quer oficiais, quer ilegais, de venda de ouro para financiamento de empresas mineiras, acções de contrabando de tungsténio, corrupção, espionagem, transferência de verbas para contas em nome de responsáveis pela economia de guerra nacional-socialista. Essas iniciativas clandestinas, contando, muitas vezes, com alguma protecção de autoridades, recorriam aos "marcados negros" de ambos os países peninsulares.

Torna-se, ainda, necessário propor um balanço sumário das motivações e dos contextos que enquadraram as posturas adoptadas pelos regimes salazarista e franquista durante e imediatamente após a Segunda Guerra Mundial. No caso português, terá ocorrido um processo de adaptação (mais ou menos eficaz) à evolução dos equilíbrios internacionais a partir de um quadro fixo de valores e objectivos. Uma tal 'estabilidade' foi mantida apesar da presença de 'sensibilidades' anglófilas/aliadófilas e germanófilas entre a base sócio-política de apoio e no seio das elites - locais/regionais, sectoriais e nacionais - do Estado Novo. Refiram-se, a este propósito, os percursos paradigmáticos de Armindo Monteiro e Fernando Santos Costa.

Entre as concepções e metas dominantes, referir-se-iam: 


\section{João Paulo Avelãs Nunes}

a) preservação da neutralidade e ampliação do grau de autonomia frente às grandes potências; inevitabilidade da dependência perante o Reino Unido e manutenção dos territórios coloniais; abastecimento do país e aproveitamento das hipóteses de crescimento económico derivadas da situação de não-beligerância; reprodução dos equilíbrios alcançados durante a década de trinta, sobrevivência de uma ditadura não-terrorista no plano interno e não-irredentista em termos externos;

b) apoio à Espanha "nacionalista" e receio das suas tendências anexionistas; recusa da lógica racista, expansionista e estatizante do nazismo em paralelo com a defesa da indispensabilidade de uma "Alemanha forte", com um "Governo de autoridade", "fronteiro de Leste" perante as "ameaças eslava e comunista", contrapeso à "ultrapassada" hegemonia do demo-liberalismo;

c) condenação do comunismo, do socialismo e da democracia em simultâneo com a crença na possibilidade de criação e afirmação internacional de um bloco de países com "regimes de ordem" (Europa da Sul e Balcânica, América Latina); apologia da "função liderante", do "destino imperial e civilizador" da Europa, desconfiança quanto aos propósitos dos EUA - símbolo máximo do "capitalismo plutocratico", do "consumo de massas", do "neo-colonialismo económico".

A estratégia adoptada contribuiu, assim, para evitar, tanto os sofrimentos e destruições resultantes de um envolvimento directo no conflito, como uma inflação descontrolada, fome e miséria generalizadas, níveis muito elevados de confrontação social. Permitiu a acumulação de riqueza (com destaque para os negócios do volfrâmio) e a revalorização do papel internacional de Portugal.

Implicou, no entanto, também, um relacionamento aprofundado com o Eixo e uma colaboração oscilante com os Aliados; dificuldades de mobilização da população para o esforço de adaptação às limitações próprias de uma conjuntura de guerra; cedências, muitas vezes contra- 
ditórias entre si, a diversos grupos de pressão; uma desigualdade crescente na distribuição dos sacrifícios e dos benefícios derivados da economia de guerra.

Acarretou, ainda, a atribuição de uma prioridade absoluta à preservação do "milagre financeiro"; a incapacidade para concretizar um projecto global de desenvolvimento regional e nacional; a recusa das oportunidades que teriam decorrido de uma integração precoce e voluntária no "bloco ocidental" - liderado pelos EUA, tendo por base um capitalismo 'temperado' por contributos keynesianos e, pelo menos no centro e na semi-periferia do sistema, regimes demo-liberais ou democráticos; centrado na Organização das Nações Unidas, Organização Económica de Cooperação Europeia/Plano Marshall, Organização do Tratado do Atlântico Norte.

Em Espanha, apesar de existirem pontos de contacto com a realidade portuguesa, a generalidade dos investiadores tem salientado a necessidade de delimitar, no período que decorre entre 1939 e 1949, pelo menos duas fases com características diferenciadas. Até meados de 1942, não chegando, nunca, a implicar uma rotura total com os Aliados, o Nuevo Estado acalentou um projecto simultaneamente autárcico-imperial e de integração no Eixo/na "nova ordem" germânica. A partir de Setembro de 1942, mantendo, embora, elevados níveis de solidariedade com a Alemanha, o Governo de Madrid adoptou uma postura mais pragmática na gestão da sua economia de guerra e das relações internacionais.

Abrandou a repressão de que eram vítimas centenas de milhar de "republicanos" derrotados na Guerra Civil (assassinados, encerrados em campos de concentração, discriminados); foram abandonadas as pretensões expansionistas e passou a exigiu-se de Berlim maiores contrapartidas em termos de fornecimento de armas e de tecnologia industrial; procurou-se rentabilizar mais eficazmente os recursos estratégicos existentes (entre os quais o tungsténio), assim como melhorar o 


\section{$\underline{\text { João Paulo Avelãs Nunes }}$}

abastecimento de bens essenciais às populações e às empresas; introduziram-se algumas mudanças na ditadura - que teria passado a ser, 'apenas', monárquica, católica, conservadora e anti-comunista - de forma a facilitar a desejada integração no bloco político-militar e económico liderado pelos EUA. Alguns desses objectivos só não foram alcançados no curto prazo devido à oposição de segmentos relevantes das opiniões públicas e das elites de muitos dos países Aliados.

No seguimento dos avisos feitos aos "países neutros" a 5 de Janeiro de 1943 e a 22 de Fevereiro de 1844, da resolução VI da Conferência de Bretton Woods (Julho de 1944), do acordo alcançado com a URSS na Conferência de Potsdam (Julho/Agosto de 1945) e das conclusões da Conferência de Paris (Novembro de 1945 a Janeiro de 1946); enquanto potências co-administrantes da Alemanha (Allied Control Council), EUA, Reino Unido e França foram encarregues de exigir da Suíça, Suécia, Espanha, Portugal e Turquia a repatriação dos cidadãos e a liquidação dos "bens alemães", a devolução do ouro monetário pilhado pelo Terceiro Reich.

Tratava-se, nesta fase inicial - pelo menos ao nível dos princípios proclamados -, de capturar e julgar os responsáveis pelos crimes cometidos pelo Eixo, de evitar o renascimento de uma Alemanha nacional-socialista (Programa Safehaven); de recolher verbas para o auxílio aos refugiados (Intergovernmental Committee on Refugees, depois, International Refugee Organization); de contribuir para a reconstrução da Europa através do pagamento de reparações e da devolução de uma percentagem tão elevada quanto possível do ouro monetário roubado - Inter-Allied Reparations Agency e Tripartite Gold

\section{Commission.}

A forma como decorreram as negociações, que se prolongaram até ao fim da década de cinquenta e que, nos últimos anos, contaram com a participação da República Federal da Alemanha, é ilustrativa das 
diferentes posturas assumidas pelo Estado Novo e pelo Nuevo Estado intransigência e flexibilidade, respectivamente; da atitude de apoio às ditaduras ibéricas adoptadas pelas potências demo-liberais - muito para além da dívida britânica a Portugal ou do interesse norte-americano pelas bases nos Açores; das transformações ocorridas no âmbito da "guerra fria", da reconstrução e desenvolvimento da Europa Ocidental, da criação, tanto da Comunidade Económica Europeia, como da Associação Europeia de Comércio Livre.

Em termos de resultados 'definitivos', depois de acordos parciais e condicionais sobre pessoas e "bens alemães" (Fevereiro de 1947), acerca do "ouro pilhado" (Junho de 1953), o Governo de Lisboa acabou por só aceitar devolver 3,998t de ouro à Tripartite Gold Commission e entregar 16 mil contos de bens liquidados à Inter-Allied Reparations Agency em 1958. Assegurou, no entanto, a entrega de 382 mil e quinhentos contos por parte da República Federal da Alemanha - pagamento das dívidas deixadas pelo Terceiro Reich, compensação do ouro devolvido, recuperação de direitos de propriedade sobre bens confiscados; o reconhecimento de que teria agido sempre "de boa fé" e "com base no direito"; a garantia de que não existiriam no futuro quaisquer outras reclamações.

O Governo de Madrid foi intimado a restituir, apenas, $101,7 \mathrm{~kg}$ de ouro, o que concordou fazer a 3 de Maio de 1948. Em compensação, os Aliados afirmaram que o regime franquista não teria tido conhecimento da origem ilegítima das barras em causa e excluíram a hipótese de outras exigências de devolução. Os "bens alemães" de natureza estatal incluindo entidades nominalmente espanholas, com destaque para o grupo Sofindus - foram liquidados logo em 1946. A 10 de Maio de 1948, assistiu-se, ainda, a um acordo sobre as empresas privadas, aplicado até 1952 com distribuição das verbas realizadas pelas duas partes contratantes. Devido às pressões exercidas pela República Federal Alemã, o processo foi suspenso e, depois, abandonado no seguimento do convénio hispano-alemão de 1958. 
O conhecimento das modalidades concretas de relacionamento entre o aparelho de Estado português e as estruturas do Terceiro Reich ligadas à guerra económica em geral e ao volfrâmio em particular, a análise do processo de identificação e liquidação dos "bens alemães" têm sido prejudicados, tanto pelo défice de desenvolvimento da história recente entre nós, como pela opacidade, inacessibilidade, desaparecimento ou destruição (total ou parcial) de muitos dos núcleos documentais pertinentes.

Refiram-se, a este propósito, os arquivos da Presidência do Conselho, Ministério da Economia, Sub-Secretaria de Estado do Comércio e da Indústria, Direcção-Geral de Minas e Serviços Geológicos/Circunscrições Mineiras, Direcção-Geral da Indústria/Circunscrições Industriais, Comissão Reguladora do Comércio dos Metais, Ministério das Obras Públicas, Transportes e Comunicações, Direcção-Geral dos Caminhos de Ferro, Direcção-Geral dos Transportes Terrestres, Ministério das Finanças, Inspecção do Comércio Bancário, Sub-Secretaria de Estado da Guerra, representação diplomática e sociedades mineiras germânicas, bancos comerciais, seguradoras, Polícia de Vigilância e Defesa do Estado, etc.

\section{Conclusão}

Considerando-se que em ambos os países ibéricos foram estruturados regimes de tipo fascista, tendencialmente totalitários, reconhece-se, no entanto, que, em relação ao Estado Novo, o Nuevo Estado apresentou, pelo menos até ao fim da década de cinquenta, mais elevados níveis de repressão. No seguimento da Guerra Civil, da conjuntura estratégico-militar que então se vivia e em resultado das afinidades político-ideológicas com o Eixo (pretensões autárcicas, expansionismo neo-imperial), durante a Segunda Guerra Mundial a maior proximidade entre a Espanha franquista e a Alemanha correspondeu aos contactos preferenciais do 
Portugal salazarista com o Reino Unido ${ }^{16}$.

Pelo menos até meados de 1942, Madrid terá abdicado de potenciar as vantagens que resultavam do estatuto de não-beligerância em favor da perseguição a centenas de milhar de "republicanos", da preparação de uma eventual entrada no conflito que fosse para além do envio da División Azul para a "Frente Leste", da subordinação à economia de guerra nacional-socialista. Em sentido inverso, Lisboa empenhou-se na defesa da neutralidade peninsular, no reforço do grau de autonomia perante as grandes potências, na atenuação das dificuldades de abastecimento, no assegurar de condições para um relativo crescimento económico e para a consolidação da situação financeira.

A partir do final de 1942, mantendo, embora, laços significativos com o Terceiro Reich, a ditadura franquista passou a atribuir maior importância às questões económico-financeiras, à sobrevivência do regime em caso de vitória Aliada, à plena integração da Espanha no "bloco capitalista" liderado pelos EUA. Sem descurar, quer os aspectos materiais, quer a reprodução da solução ditatorial imposta no início da década de trinta, o regime salazarista acentuou o seu empenhamento na luta por outros valores ideológicos e concepções estratégicas encarados como fundamentais: a recusa da industrialização e urbanização aularadas, do capitalismo monopolista e do consumo de massas; a defesa do papel liderante de uma Europa "cristã, colonizadora e civilizadora", da importância de uma Alemanha poderosa, adversário irredutível do comunismo, da viabilidade de uma coligação de países com "Governos de ordem".

${ }^{16}$ Cfr., nomeadamente, J. Catalan, 1995; E. Collotti, 1992; M. Espadas Burgos, 1988; R. Garcia Pérez, 1994; J.C. Jiménez Redondo, 1996; Ch. Leitz, 1996; M. Loff, 1997; J.P.A. Nunes, 1993; J.P.A. Nunes, s.d.; P. Preston, 1995; F. Rosas, 1990; K.-J. Ruhl, 1986; A.J. Telo, 1991; A.J. Telo, 1999; N. Valério, 1994. 
Parece, assim, ser legítimo e operatório avançar com a hipótese segundo a qual, em termos de guerra económica, mesmo considerando o Acordo de Pagamentos luso-britânico de Novembro de 1940, os Aliados teriam encontrado maiores dificuldades em Portugal do que em Espanha. Por sua vez, a Alemanha estabeleceu com o Estado Novo uma relação menos assimétrica e mutuamente mais proveitosa - excepção feita às acções de afundamento de navios mercantes e pesqueiros nacionais - do que a imposta ao Nuevo Estado, em grande parte baseada na exigência de entrega de bens estratégicos a título de pagamento da dívida acumulada durante a Guerra Civil.

Simultaneamente actores e estudiosos da guerra económica travada entre 1939 e 1945, assim como John H. Kemler e William Norton Medlicott, também David L. Gordon/Royden Dangerfield afirmaram: "In spite of all our financial difficulties in Spain, in spite of the pronounced proAxis cast of the Franco Government, and in spite of the fact that the output of strategic materials was at times controlled by interests friendly to the enemy or had been allocated to the enemy in advance, preclusive buying as a technique of economic warfare worked best in Spain."

Obstáculos vários, resultantes, entre outros factores, da natureza clandestina de muitas das transacções concretizadas, da multiplicidade de entidades (oficiais e privadas) envolvidas, continuam a impedir uma quantificação rigorosa dos diversos componentes do dossier "tungsténio peninsular (1940 a 1945)". É, apesar de tudo, impossível deixar de reconhecer a importância alcançada pelo volfrâmio, tanto nas economias de guerra portuguesa e espanhola, como na guerra económica travada entre o Eixo e os Aliados; o facto de Berlim ter obtido proporcionalmente melhores resultados entre nós do que junto dos nossos vizinhos. 
A relevância deste indicador para a compreensão da postura adoptada por cada uma das ditaduras ibéricas surge, ainda, reforçada quando se lembram alguns vectores de contextualização: o peso das empresas britânicas no subsector nacional do tungsténio em 1939, as afinidades político-ideológicas e estratégico-militares entre Madrid e a Alemanha nacional-socialista, a forma como decorreram e terminaram as negociações que levaram, quer ao embargo das exportações de volfrâmio espanhol para o Terceiro Reich, quer à suspensão da produção e venda de concentrados portugueses. 


\section{DOCUMENTAÇÃO E BIBLIOGRAFIA}

AFONSO, Rui, Injustiça, O caso Sousa Mendes, Lisboa, Editorial Caminho, 1990.

BARROS, Júlia Leitão de, O fenómeno de opinião em Portugal durante a Segunda Guerra Mundial, Lisboa, 1993 (policopiado).

BEKER, Avi, Unmasking national myths: europeans challenge their history, Jerusalém, Institute of the WJC, 1997.

BOWER, Tom, L'or nazi. Les banques suisses et les juifs (trad. do inglês), Paris, Librairie Plon, 1997.

CATALAN, Jordi, La economía española y la Segunda Guerra Mundial, Barcelona, Editorial Ariel, 1995.

COLLOTTI, Enzo, Fascismo, fascismos (trad. do italiano), Lisboa, Editorial Caminho, 1992.

Comércio Externo [1940-1944].

Correspondencia de Pedro Teotónio Pereira para Oliveira Salazar (1931-1944), 4 volumes, Lisboa, CLNRF, 1987-1991.

Dagens Nyheter ("Kultur Special") (trad. do sueco), 21 de Outubro de 1997 ("Sweden and the nazi gold").

The Deutsche Bank and its gold transactions during the Second World War, Munique, Historical Comission, 1998 (online version).

Dez anos de política externa (1936-1948). A nação portuguesa e a Segunda Guerra Mundial, 15 volumes, Lisboa, MNE/IN, 1961-1993.

DURAND, Yves, Le nouvel ordre européen nazi: la collaboration dans l'Europe allemande (1938-1945), Bruxelas, Éditions Complexe, 1990.

Enterprises in the period of fascism in Europe. Conference (Paris, Bibliothèque Nationale de France, 26/27 Novembre 1988), Paris, The Society for European Business History, 1998 (online version).

ESPADAS BURGOS, Manuel, Franquismo y politica exterior, Madrid, Ediciones Rialp, 1988.

O fim da Segunda Guerra Mundial e os novos rumos da Europa. Actas do Coloquio, Lisboa, IHC da FLL/Edições Cosmos, 1996.

FIOR, Michel, La Banque Nationale Suisse et l'or allemand (1939-1945), Neuchâtel, 1996 (policopiado).

GARCÍA PÉREZ, Rafael, Franquismo y Tercer Reich. Las relaciones económicas hispano-alemanas durante la Segunda Guerra Mundial, Madrid, Centro de Estudios Constitucionales, 1994. 
GILBERT, Martin, A Segunda Guerra Mundial (trad. do inglês), 2 volumes, Lisboa, Publicações Dom Quixote, 1989.

GOLDHAGEN, Daniel Jonah, Les bourreaux volontaires de Hitler. Les allemands ordinaires et l'holocauste (trad. do inglês), Paris, Éditions du Seuil, 1997.

GORDON, David L. e DANGERF1ELD, Royden, The hidden weapon. The Story of economic warfare, Nova Iorque, Harper \& Brothers Publishers, 1947.

GRANT, Wyn e outros (org.), Organising business for war. Corporatist economic organisation during the Second World War, Oxford, Berg Publishers, 1991.

HARRISON, Mark, The economics of World War II. Six great powers in international comparison, Cambridge, CUP, 1998.

HEDIN, Sven Frederik e ELGEMYR, Goran, Sweden and the Shoah, Jerusalém, Institute of the WJC, 1997.

História, II Série, Ano XVII, ${ }^{\circ}$ 7, Abril de 1995, p. $4-49$ ("Política de arquivos: crime sem castigo").

História, II Série, Ano XVII, n ${ }^{\circ}$, Maio de 1995, p. 4-61 ("Portugal e a II Guerra").

Informe para la Comisión de investigación de las transacciones de oro procedente del Tercer Reich durante la Segunda Guerra Mundial, Madrid, 1998 (policopiado).

JANEIRO, Helena Pinto, Salazar e Pétain. Relações luso-francesas durante a II Guerra Mundial (1940-44), Lisboa, Edições Cosmos, 1998.

JIMÉNEZ REDONDO, Juan Carlos, Franco e Salazar. As relações lusoespanholas durante a Guerra Fria, Lisboa, Assírio \& Alvim, 1996.

KEMLER, John H., The struggle for wolfram in the Iberian Peninsula (June, 1942-June, 1944). A study in political and economic geography in wartime, Chicago, 1949 (policopiado).

LEITE, João Pinto da Costa, Economia de guerra, Porto, Livraria Tavares Martins, 1943.

LEITE, Joaquim da Costa, Nota breve sobre as transacções de ouro do Banco de Portugal (1939-45). Banco de Portugal: ouro (1937-1946), Lisboa, 1997 (policopiado).

LEITZ, Christian, Economic relations between nazi Germany and Franco's Spain (1936-1945), Oxford, OUP, 1996.

LI, K.C. e WANG, Chung Yu, Tungsten, Nova Iorque, Reinhold Publishing Corporation, 1955, $3^{2}$ edição. 
LIECHTI, Myriam, Le Portugal et la Suisse: des relations etonnantes de 1941 a 1943, Neuchâtel, 1997 (policopiado).

LOFF, Manuel, Salazarismo e franquismo na época de Hitler (1936-1942), Porto, Campo das Letras, 1997.

LOUÇÃ, António, "Budapeste, 1944: dois diplomatas portugueses face ao holocausto", História, II Série, Ano XVIII, n ${ }^{\circ}$ 15, Dezembro de 1995, p. 24 -33 .

LOUÇÃ, António, "Da receptação às negociações do pós-guerra. Portugal e o ouro roubado pelos nazis", História, II Série, Ano XVIII, $n^{\circ} 25$, Outubro de 1996, p. 4-21.

LOUÇÃ, António, "Salazar, o holocausto e o ouro nazi", História, II Série, Ano XIX, n 30, Abril de 1997a, p. 4-13.

LOUÇÃ, António, Negócios com os nazis. Ouro e outras pilhagens (1933-1945), Lisboa, Fim de Século, 1997b.

LOUÇÃ, António, "As armas alemãs de Salazar (1936-1944)", História, III Série, Ano XXI, $n^{\circ}$ 12, Março de 1999a, p. 16-26.

LOUÇÃ, António, "Ouro escondido", Expresso, 15 de Maio de 1999b, p. 6/7. LOUÇÃ, António, "Relatório Soares. Vinho velho em odres novos", História, III Série, Ano XXI, ${ }^{\circ}$ 18, Outubro de 1999c, p. 84-86.

LOUÇÃ, António, "Novo olhar sobre o ouro nazi", História, III Série, Ano XXI, ${ }^{\circ}$ 20, Dezembro de 1999d, p. 82-84.

MEDLICOTT, William Norton, The economic blockade, 2 volumes, Londres, HMS Office/Longmans, Green and $C^{\circ}$, 1952-1959.

MELLO, Manuel Homem de, Eu vi morrer o III Reich, Lisboa, Editorial Vega, 1982.

MIEDZIANAGORA, G., e JOFER, G., Objectivo externínio. Vontade, resolução e decisões de Hitler (trad. do francês), Lisboa, Editorial Vega, 1995.

MILLER, Richard Lawrence, Justiça nazi. A lei do holocausto (trad. do inglês), Lisboa, Editorial Notícias, 1997.

The nazi gold and the Swedish Riksbank. interim report (trad. do sueco), Estocolmo, The Commission on Jewish Assets in Sweden at the time of the Second World War, 1998.

NUNES, Isabel Ferreira, "Delineamento de uma estratégia diplomática portuguesa. Portugal na Segunda Guerra Mundial", Estratégia, vol. V, 1993, p. 53-297.

NUNES, João Paulo Avelãs, "O conceito de "fascismo" na história recente de Portugal", Vértice, II Série, n 52, Janeiro/Fevereiro de 1993, p. 53-65. 
NUNES, João Paulo Avelãs, "Volfrâmio português e ouro do Terceiro Reich durante a Segunda Guerra Mundial (1938-1947)" [aguarda publicação na revista Vértice], s.d.

OLIVEIRA, Pedro Aires, Armindo Monteiro: uma biografia política, Lisboa, 1998 (policopiado).

PAXTON, Robert O., Vichy France. Old Guard and New Order (1940-1944), Nova Iorque, Columbia University Press, 1992, $2^{\mathrm{a}}$ edição.

PETER, Felicitas von, British policy towards Portugal in the Second World War, Cambridge, 1995 (policopiado).

PIMENTEL, Irene, "Portugal, porto de abrigo. Refugiados durante a II Guerra Mundial", História, 3ª́rie, Ano XX, n 8, Novembro de 1998, p. 16-25. PIMENTEL, Irene, "O anti-semitismo português na primeira metade do século XX: marginal e importado", História, 3 $3^{\text {a }}$ Série, Ano XXI, ${ }^{\circ}$ 15, Junho de 1999, p. 42-53.

Portugal na Segunda Guerra Mundial. Contributos para uma reavaliação, Lisboa, Publicações Dom Quixote, 1989.

PRESTON, Paul, The politics of revenge. Fascism and the military in 20 thcentury Spain, Londres, Routledge, 1995, $2^{\text {a }}$ edição.

Relatório da Comissão de Investigação Sobre as Transacções de Ouro Efectuadas Entre as Autoridades Portuguesas e Alemãs Durante o Período Compreendido Entre 1936 e 1945, Lisboa, 1999 (policopiado).

RODRIGUES, Manuel Ferreira, "Arquivos das empresas: património ignorado", Estudos Aveirenses, ${ }^{\circ}$ 1, 1993, p. 151-163.

RODRIGUEZ PÉREZ, José Alberto, "A minaria do volfrámio em Galiza (1887-1960). Umha primeira aproximaçom", Agália, $n^{\circ}$ 2, 1985, p. 49-70.

ROLLO, Fernanda, Portugal e o Plano Marshall. Da rejeição à solicitação da ajuda financeira norte-americana (1947-1952), Lisboa, Editorial Estampa, 1994.

ROSAS, Fernando, Portugal entre a paz e a guerra (1939-1945). Estudo do impacte da II Guerra Mundial na economia e na sociedade portuguesas, Lisboa, Editorial Estampa, 1990.

ROSAS, Fernando (coord.), O Estado Novo (1926-1974), MATTOSO, José (dir.), História de Portugal, vol. 7, Lisboa, Círculo de Leitores, 1994.

ROSAS, Fernando e outros (coord.), Armindo Monteiro e Oliveira Salazar. Correspondência política (1926-1955), Lisboa, Editorial Estampa, 1996. ROSAS, Fernando, "O ouro nazi e a mulher de César", Público, 10 de Julho de 1999, p. 11. 
RUBY, Marcel, O livro da deportação. A vida e a morte nos 18 campos de concentração e de extermínio (trad, do francês), Lisboa, Editorial de Notícias, 1998.

RUHL, Klaus-Jorg, Franco, Falange y "Tercer Reich ". España en la Segunda Guerra Mundial (trad. do alemão), Madrid, Ediciones Akal, 1986.

RUIZ MORALES, José Miguel, La economia del bloque hispano-portugués, Madrid, Instituto de Estudios Políticos, 1946.

SALAZAR, António de Oliveira, Discursos e notas políticas, 6 volumes, Coimbra, Coimbra Editora, 1945-1967.

SOBRAL, Fernando Sousa e Silva e MATIAS, Manuel João Senos, Volfrâmio: aspectos técnico-económicos, Coimbra, FCTUC, 1982, 2 edição (policopiado).

STONE, Glyn A., The oldest ally. Britain and the Portuguese connection (1936-1941), Londres, The Royal Historical Society/The Boydell Press, 1994.

Sweden and Jewish assets (trad. do sueco), Estocolmo, The Commission on Jewish Assets in Sweden at the time of the Second World War, 1999.

SWEENEY, Jerry K, "The Portuguese wolfram embargo: a case study in economic warfare", Military Affairs, Fevereiro de 1974, p. 23-26.

Switzerland and gold transactions in the Second World War. Interim report, Berna, Independent Commission of Experts Switzerland-Second World War, 1998 (policopiado).

TELO, António José, Portugal na Segunda Guerra Mundial, Lisboa, Perspectivas \& Realidades, 1987.

TELO, António José, Portugal na Segunda Guerra Mundial (1941-1945), 2 volumes, Lisboa, Editorial Vega, 1991.

TELO, António José, Portugal e a NATO. O reencontro da tradição atlântica, Lisboa, Edições Cosmos, 1996.

TELO, António José, O ouro nazi. Relações económicas e financeiras entre Portugal e a Alemanha (1939-1958), Lisboa, 1999 (policopiado).

U.S. and Allied efforts to recover and restore gold and other assets stolen or hidden by Germany during World War II, 2 volumes, Washington, 1997/ 1998 (policopiado).

VALERIO, Nuno, As finanças públicas portuguesas entre as duas guerras mundiais, Lisboa, Edições Cosmos, 1994.

Vértice, II Série, ${ }^{\circ}$ 69, Novembro/Dezembro de 1995, p. 3-155 ("A Segunda Guerra Mundial 50 anos depois..."). 


\section{Portugal, Espanha, o volfrâmio e os beligerantes}

VICENTE, Ana, Portugal visto pela Espanha. Correspondência diplomática (1939-1960), Lisboa, Assírio \& Alvim, 1992.

VILAR, António, O volfrâmio de Arouca. No contexto da Segunda Guerra Mundial (1939-1945), Arouca, CMA, 1998.

WHEELER, Douglas L., "The price of neutrality: Portugal, the wolfram question and World War II", Luso-Brasilian Review, vol. 23, ${ }^{\circ}$ 1, Verão de 1986, p. 107-127; $\mathbf{n}^{\circ}$ 2, Inverno de 1986, p. 97-111.

ZIEGLER, Jean, A Suiça, o ouro e os mortos. A questão do ouro nazi (trad. do alemão), Lisboa, Terramar, 1997. 